\title{
A Case Study on Job Stress Prevention in Shipbuilding Industry
}

\author{
Chang-Ho Bae ${ }^{1}$, Yu-Chang Kim ${ }^{2}$ \\ ${ }^{1}$ Group of HSE, Samsung Heavy Industry, Geoje, 656-710 \\ ${ }^{2}$ Department of Industrial Management Engineering, Dong-eui University, Busan, 614-714
}

\begin{abstract}
Objective: The aim of this study is to introduce activities for job stress management in shipbuilding industry. Background: Recently, workers are exposed many job stress like workload, interpersonal conflict while management condition of company changes day by day. Particularly, shipbuilding industry has poor environment which aggravating the stress to the workers. So managing job stress may be more important. Method: The method of this study is to investigate preventive actions of job stress in "S" shipbuilding company. Results: This study through case of "S" shipbuilding company introduce activities of prevention of job stress including identification of level of job stress, managing of psychological clinic, training of worker and manager. Conclusion: In order to manage the job stress in the workplace, 1) The total management system based on the concern of the management in the workplace has to be constructed. 2) Computerized system for operation of total management system has to be constructed. 3) New employees need training for Job Stress. Application: Through this case study, I hope to help prevention activities of job stress in the workplace.
\end{abstract}

Keywords: Shipbuilding industry, Job stress

\section{Introduction}

오늘날 기업들은 세계화에 따른 글로벌 경영, 선택기회의 다양성, 고객의 기대 상승 등으로 기업을 둘러싼 경영환경이 나날이 변화하고 있다. 이에 따라 작업자들은 업무량, 책임 감, 역할갈등, 대인간 갈등 등과 같은 많은 직무스트레스에 노출되어 있다. 특히, 조선업은 일반 제조업과는 달리 작업 에 대한 강도가 크며, 조선업의 특성상 협소한 공간, 빈번한 작업장 이동, 작업의 복잡성, 구조물의 위험성 등과 같은 특 수한 환경을 가지고 있다(Hong, 2011).

이와 같은 열악한 작업환경은 작업자의 직무스트레스를 유발하거나 가중시킬 수 있으며, 작업자 개인 삶의 질에 커 다란 영향을 미치고, 결국 이는 다양한 질병의 원인으로 작 용한다. 따라서, 일반 제조업에서의 직무스트레스에 대한 관
리도 중요하지만, 조선업에서의 직무스트레스 관리는 더욱 중요한 부분을 차지한다고 할 수 있다.

직무스트레스는 주변환경의 요구와 개인의 능력이 맞지 않거나, 개인적 요구와 기대를 환경이 맞추지 못하였을 때 발생하며, 그 원인으로는 높은 작업부하, 긴 작업시간, 의사 결정의 부족뿐 아니라 작업공간의 부족, 소음, 조명과 같은 위험한 환경조건, 기타 인간공학적인 문제 등이 있다(Kim and Bae, 2006).

직무스트레스로 인한 건강장애로는 뇌출혈, 뇌경색, 심근 경색, 협심증, 고혈압, 편두통, 소화성 궤양 등이 있으며(Han et al., 2003), 직무스트레스와 관련된 정신 질환은 모든 작 업 관련성 질환의 $1 / 3$ 을 차지하고(HSE, 1999), 조기퇴직의 $20 \%$ 를 차지하고 있다는(Pattani et al., 2001) 보고 등 많은 연구에 의해서 직무스트레스 관리의 중요성을 언급하고 있 다. 이에 따라 국내에서도 직무스트레스와 관련된 연구가

Corresponding Author: Yu-Chang Kim. Department of Industrial Management Engineering, Dong-eui University, Busan, $614-714$.

Mobile: 018-451-6114, E-mail: yckim@deu.ac.kr

Copyright@2012 by Ergonomics Society of Korea(pISSN:1229-1684 eISSN:2093-8462). All right reserved. 
활발히 이루어지고 있으며, 특히 지하철 기관사(Jung and Kim, 2006), 간호사(Lee, 1984), 유통업 종사자(Yoon and Park, 2008), 초등학교 교사(Kang, 2004), 통신업 근로자 (Park et al., 2005), 조선업 종사자(Kim and Chang, 2011), 항공 정비 근로자(Song et al., 2007) 등 다양한 직군의 종 사자들을 대상으로 한 직무스트레스 수준과 요인의 특성이 제시되고 있다.

뿐만 아니라, 우리나라에서도 직무스트레스에 대한 관리의 중요성을 인식하여 산업보건기준에 관한 규칙 제259조(직 무스트레스에 의한 건강장해 예방조치)에 의거하여 종사자 의 개인 또는 직장에서의 부서 및 회사 전체의 집단적 직무 스트레스 요인의 수준을 표준화된 한국인 직무스트레스 요 인 측정도구를 사용하여 평가하고, 적절한 조치를 취하도록 규정하고 있다(KOSHA, 2006).

앞서 언급한 바와 같이 직무스트레스는 여러 가지 질병의 원인이 될 수 있으며, 이는 사업장에서의 생산성 저하로 인 한 경제적 손실도 야기할 수 있으므로 총체적인 관리가 필 요한 실정이다. 그러나, 사업장에서의 직무스트레스 관리는 대기업을 중심으로 일부 이루어지고 있는 실정이다. 따라서, 본 논문에서는 직무스트레스 관리를 위한 여러 가지 활동 사 례의 소개로 직무스트레스 관리에 대한 정보를 공유하고, 운 영 중에 발생할 수 있는 문제점을 파악하여 개선방향을 제시 하고자 한다.

\section{Method}

\subsection{Identification and measurement of the level of job stress}

직무스트레스에 대한 모델은 수많은 연구에 의해 제시되 었다. $\mathrm{NIOSH}$ 에서의 직무스트레스 모델에서는 직무스트레스
란, 작업, 조직, 환경적 요인에 의해 발생되어 그 결과로 행 동적 반응이 일어나게 되며, 이런 반응들이 지속되면 결국 다양한 질병에 이르게 됨을 설명하고 있다. 즉, 직무스트레 스로 인해 우울증, 혈압상승, 대인관계 장애, 수면장애, 업무 능력 저하 등의 반응이 나타나고, 이러한 반응들이 뇌심혈 관계 질환, 정신 질환 등의 질병으로 이르게 됨을 제시하고 있다.

사업장에서 직무스트레스의 적절한 관리를 위해서 우선되 어야 하는 것은 관리대상의 선정이며, 이에 사업장에서 쉽게 접근할 수 있는 방법은 설문도구를 이용한 방법이다. 지금까 지 직무스트레스에 대한 설문 연구는 주로 Karasek 모델 등 기존에 외국에서 개발된 설문을 이용한 것이 다수이다. 물론 이는 많은 연구에 의해서 타당성과 신뢰성을 확보하였 으나, 단순히 한국어로 번역하여 사용하는 것에는 한국의 작 업환경에서 비롯되는 정서를 반영하기에는 많은 한계를 가 지고 있다(Choi, 2005)

이에 따라 2005년 한국산업안전보건공단에서 전국 30,000 명 이상의 작업자를 대상으로 신뢰도와 타당도 검증의 과 정을 거쳐 개발된 한국인 직무스트레스 측정도구인 $\mathrm{KOSS}$ (Korean Occupational Stress Scale)를 개발하였고, KOSS 설문을 이용한 연구가 활발히 진행되고 있다. KOSS 설문 기 본형은 물리환경, 직무요구, 직무자율, 관계갈등, 직업불안정, 조직체계, 보상부적절, 직장문화의 총 8 개 수준에 43 개 문항 (단축형 24문항으로 구성)으로 구성되어 있다.

$\mathrm{KOSS}$ 설문지는 작업자의 직무스트레스 요인을 측정하는 데 주안점을 두었으며, 그 외의 가정영역은 포함되지 않았다. 그리고 직무스트레스 결과로서의 증상수준을 측정하는 것이 아니라 직무스트레스의 요인을 평가하기 위한 것이다. 따라 서 본 사업장에서는 KOSS 설문 단축형 24문항과 더불어 일상생활에서의 직무스트레스 확인을 위해 일반 직무스트레 스 10항목, 직무스트레스로 인한 반응 확인을 위해 우울 20 항목, 불안 21항목, 수면 습관 9항목 총 84 개 항목의 설문

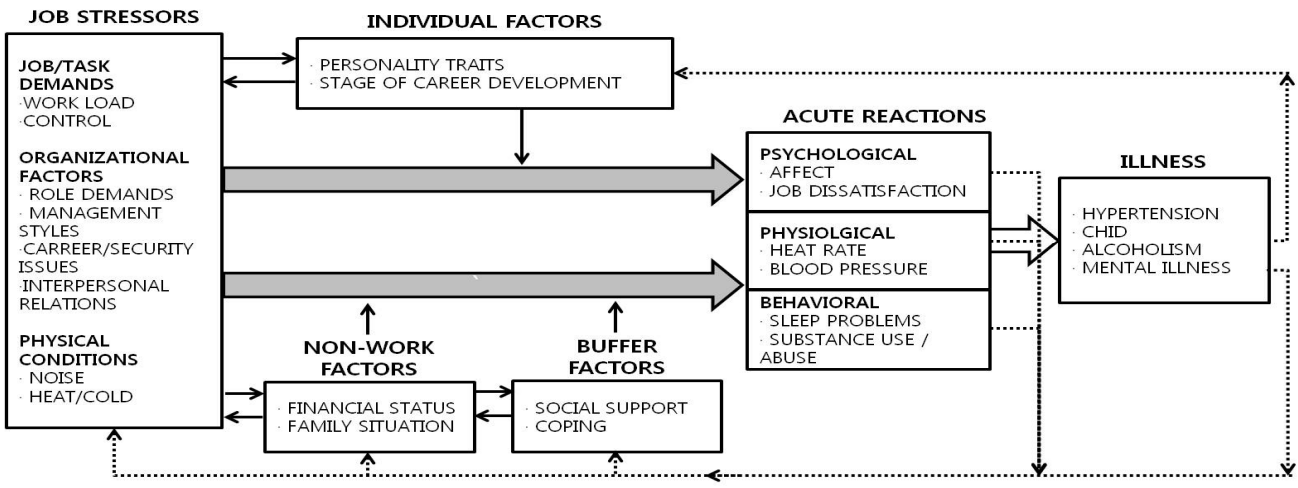

Figure 1. NIOSH job stress model 
을 실시하였다.

직무스트레스 총점은 37.80점으로 $\mathrm{KOSS}$ 에서 제공하고 있는 평가분류 중 매우 낮은 점수(42.4 이하)로 분류되나, 30 대 이하에서 직무요구 및 직무자율 항목이, 50대 이상에 서는 직무불안정 항목이 가장 높게 나타났다.

그리고 설문 외에 심박동수 변이 측정기(HRV, Heart Rate Variability)를 통해 자율신경 균형검사를 실시하고 있다. 이 는 심장박동수의 변화도를 이용하여 자율신경계의 항상성 조절 메커니즘을 추적하여 직무스트레스 상태를 추정하는 검사방식으로 이를 통해 자율신경활성도, 직무스트레스 상태 를 측정할 수 있다.

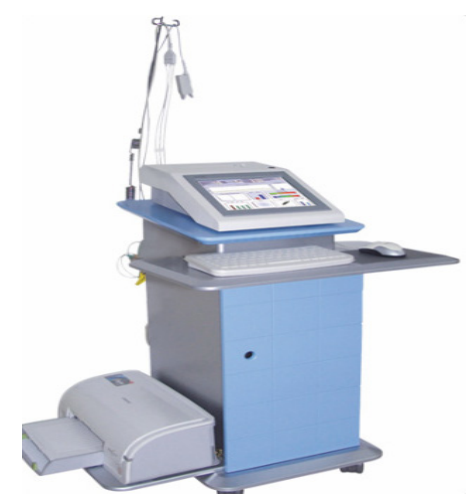

Figure 2. Heart rate variability

이렇게 측정된 모든 데이터를 종합하여 안정, 불안정, 소 진, 심각의 4 단계로 분류하여 관리한다.

Table 1. Stage classification and information

\begin{tabular}{c|c|l}
\hline Phase & State & \multicolumn{1}{c}{ Contents } \\
\hline Phase I & Stability & Unnecessary special action \\
\hline Phase II & Instability & Necessary preventive action \\
\hline Phase III & Exhaustion & Need relief efforts exhausted \\
\hline Phase IV & Severity & $\begin{array}{l}\text { Necessary comprehensive stress } \\
\text { management }\end{array}$ \\
\hline
\end{tabular}

\subsection{Methods of job stress management}

\subsubsection{Operation of psychological clinics and counseling center}

직무스트레스 수준을 확인하게 되면, 그에 따른 적절한 치 료방법 선택을 통한 신속한 조치가 이루어져야 한다. 특히 조선업의 경우 많은 중량물 운반작업이 이루어지고, 고소작 업, 화기작업 등의 작업환경을 가지고 있기 때문에 과도한
직무스트레스로 인한 불안정한 심리상태는 안전사고와도 직 결될 수 있으므로 상담 및 치료 등의 신속한 조치가 매우 중 요하다. 이에 따라 사내에 전문인력 확보 및 장비 구축을 통 해 심리치료실을 운영하고 있다.

심리치료실은 직무와 관련된 요인들의 해소를 위해 직무 스트레스 검사실, 상담실, 심리안정치료 및 명상실로 구성하 여 직무스트레스 검사, 심리안정치료, 개인상담을 실시하고 있다. 상담 내용은 철저히 비밀 보장되며, 상담에 대한 조치 로는 문제해결을 위한 대안이나 방향을 제시한다. 단, 상담 사의 판단에 의해 안전, 보건상의 위험이 예상되는 경우 본 인 수용 범위 내에서 관련 협의를 통해 작업전환, 잔업관리, 휴직치료 등의 조치가 이루어진다.

Table 2. Psychological clinics for examination and treatment

\begin{tabular}{c|l}
\hline Classification & \multicolumn{1}{|c}{ Contents } \\
\hline \multirow{2}{*}{ Stress test } & $\begin{array}{l}\text { Function of brain, autonomic nervous system, } \\
\text { function of heart }\end{array}$ \\
\hline \multirow{4}{*}{$\begin{array}{c}\text { Treatment } \\
\text { of stable } \\
\text { psychological }\end{array}$} & $\begin{array}{l}\text { Biofeedback training } \\
\text { (relaxation of the heart, enhanced concentration) }\end{array}$ \\
\cline { 2 - 2 } & $\begin{array}{l}\text { Treatment of sound and vibration(relaxation of the } \\
\text { heart through sound and vibration) }\end{array}$ \\
\cline { 2 - 2 } & $\begin{array}{l}\text { Stability of psychology and meditation } \\
\text { (lighting, sound, aroma, color therapy) }\end{array}$ \\
\cline { 2 - 2 } & $\begin{array}{l}\text { Mental and physical relaxation } \\
\text { (muscle relaxation technique, stretching) }\end{array}$ \\
\hline $\begin{array}{c}\text { Personal } \\
\text { counseling }\end{array}$ & Psychology, stress, health, character, self-exploring \\
\hline
\end{tabular}
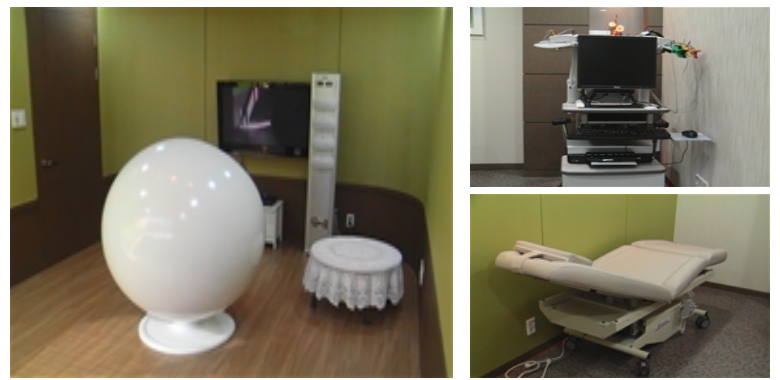

Figure 3. Psychological clinics of major equipment

직무스트레스는 다양한 요인으로 발생한다. 직장 내 대인 관계, 작업환경뿐 아니라 개인적인 요인에 의해서도 발생할 수 있다. 한가지 요인이 아닌 다른 요인들과 복합적으로 작 용할 수 있고, 다른 직무스트레스 요인의 한 요인으로도 작 용할 수 있기 때문에 작업, 조직, 환경에 의한 직무스트레스 요인 뿐 아니라 부부갈등 등과 같은 개인적 직무스트레스 요인을 포함한 총체적인 직무스트레스 관리가 필요하다. 
심리치료실은 직무와 관련된 직무스트레스의 치료 및 조 치에 초점을 맞춘 것이다. 그러나 앞서 언급한 바와 같이 직 무스트레스의 관리를 위해서는 개인적인 요인에 대한 부분 도 동시에 조치가 이루어져야 한다. 이에 열린상담센터를 심 리치료실과 별도로 운영하고 있다. 열린상담센터에서는 외부 전문 상담사를 2회/주 초빙하여 인간관계, 부부갈등, 자녀지 도, 성격문제, 미래설계 등 일상생활 속에서 겪을 수 있는 다양한 개인적 고민에 대한 상담을 제공하고 있다.

\subsubsection{Education of job stress}

직무스트레스 교육은 관리자 교육과 사내 업무시스템을 활용한 홍보로 구분하여 실시하고 있다. 관리자 교육내용은 작업자와의 상담이 제일 먼저 해당 조직의 일선관리자와 이 루어짐을 감안하여 문제해결적 대화기법, 상담자 태도에 따 른 면담기법, 효과적인 대화기법과 같은 내용으로 작업자와 의 상담기법에 대하여 초점을 두고 있다. 사내 업무시스템을 통한 홍보내용으로는 명상법, 가벼운 운동법 등과 같은 대부 분 개인 직무스트레스 대체 기술에 초점을 두고 이루어지고 있으며, 향후 다양한 교육내용 개발을 통한 커리큘럼 확보가 요구된다.

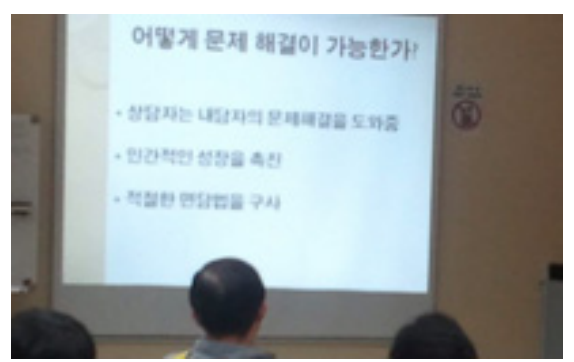

Figure 4. Education of job stress

\subsubsection{Management of job stress and cerebral -cardiovascular disease}

뇌심혈관계 질환은 뇌혈관 및 심장혈관계와 관련된 질환 을 의미한다. 대표적인 질병으로 허혈성 심장 질환, 뇌경색 등이 있다. 뇌심혈관계 질환은 고혈압, 고지혈증, 흡연, 비만, 음주 등의 다양한 요인에 의해 나타나며, 직무스트레스도 그 요인 중 하나이다.

직무스트레스와 뇌심혈관계 질환과의 관련성은 많은 연구 에서 언급되었다. 정신적 직무스트레스를 증오감과 $\mathrm{A}$ 형 성 격, 우울증과 불안, 직무스트레스, 사회적 지지의 4 가지 영 역으로 분류하여 분석하였다. 정신적 직무스트레스가 뇌심혈 관계 질환의 원인이 되는가에 대해 실시한 코호트 연구에서 $\mathrm{A}$ 형 성격 및 증오감 등은 14 개 연구 중 6 개 연구에서 관련
성이 있었고, 상대 위험도는 대개 1.4에서 2.6으로 나타났다. 우울증과 불안은 11 개 연구 모두 연관성이 있었고 상대 위 험도는 1.18 에서 5.4 로 조사되었다. 직무스트레스는 10 개 연구 중 6 개의 연구에서 연관성이 있었고 상대 위험도는 1.4 에서 4.59 로 나타났으며, 사회적 지지에서는 8 개 연구 중 5 개 연구에서 연관성이 있었으며 상대 위험도는 1.14 에 서 3.8로 나타났다(Hemingway and Marmot, 1999).

뇌심혈관계 질환은 다른 작업 관련성 질환에 비해 사망률 이 높으며, 사망에 이르지 않더라도 결국 장기적인 치료나 후유증을 남기기 때문에 직무스트레스 관리와 함께 특별한 관리가 필요하다. 따라서, 본 사업장에서의 뇌심혈관계 질환 의 발병 위험도 평가 및 사후 관리에 대해 소개한다.

사내에서 건강검진이 실시된다. 검진결과로 확보된 혈압, 고지혈증, 당뇨, 생활습관(흡연, 운동여부 등), 과거력(뇌졸 증, 심근경색증 등)을 종합하여 3등급으로 분류하고 등급에 따라 사내 병원에서 생활습관, 약물치료 등의 사후 관리가 이루어진다.

Table 3. Stage classification and information

\begin{tabular}{|c|c|c|c|}
\hline \multirow{2}{*}{$\begin{array}{r}\text { Risk } \\
\text { factor } \\
\text { Blood } \\
\text { pressure } \\
(\mathrm{mmHg})\end{array}$} & \multirow[b]{2}{*}{$\begin{array}{l}\text { No additional } \\
\text { risk factors }\end{array}$} & \multicolumn{2}{|c|}{ Risk factors exists one more } \\
\hline & & $\begin{array}{l}\text { Hyperlipidemia, } \\
\text { diabetes, } \\
\text { smoking etc. }\end{array}$ & $\begin{array}{c}\text { Stroke, kidney } \\
\text { failure, angina etc. }\end{array}$ \\
\hline \multirow{2}{*}{$\begin{array}{c}140 \sim 159 / \\
90 \sim 99\end{array}$} & $\begin{array}{c}\text { Lifestyle } \\
\text { management }\end{array}$ & \multicolumn{2}{|c|}{ Lifestyle management / drug treatment } \\
\hline & $\begin{array}{c}\text { Confirmed } \\
\text { within } 8 \text { weeks }\end{array}$ & \multicolumn{2}{|c|}{ Confirmed within 8 weeks } \\
\hline \multirow{2}{*}{$\begin{array}{c}160 \sim 179 / \\
100 \sim 109\end{array}$} & \multicolumn{2}{|c|}{$\begin{array}{l}\text { Lifestyle management / } \\
\text { drug treatment }\end{array}$} & $\begin{array}{l}\text { Limit of working } \\
\text { time / lifestyle } \\
\text { management / }\end{array}$ \\
\hline & $\begin{array}{c}\text { Confirmed } \\
\text { within } 4 \text { weeks }\end{array}$ & $\begin{array}{l}\text { Reassessment } \\
\text { within } 4 \text { weeks }\end{array}$ & $\begin{array}{l}\text { Reassessment } \\
\text { within } 2 \text { weeks }\end{array}$ \\
\hline \multirow[t]{2}{*}{$\begin{array}{l}>180 / \\
>110\end{array}$} & $\begin{array}{l}\text { Limit of } \\
\text { working time / } \\
\text { lifestyle } \\
\text { management / } \\
\text { drug treatment }\end{array}$ & $\begin{array}{l}\text { Limit of } \\
\text { working time / } \\
\text { lifestyle } \\
\text { management / } \\
\text { drug treatment / } \\
\text { examination }\end{array}$ & $\begin{array}{c}\text { Lifestyle } \\
\text { management / } \\
\text { drug treatment / } \\
\text { examination / } \\
\text { sick leave / } \\
\text { Absence }\end{array}$ \\
\hline & $\begin{array}{c}\text { Confirmed } \\
\text { within } 4 \text { weeks }\end{array}$ & $\begin{array}{l}\text { Reassessment } \\
\text { within } 1 \text { weeks }\end{array}$ & - \\
\hline
\end{tabular}

이와 더불어 사내 의사 및 간호 인력을 활용하여 고혈압, 당뇨, 고지혈증 예방 및 치료, 생활습관 개선, 뇌심혈관 질환 예방법에 대한 내용으로 '찾아가는 보건교육'을 실시하고 있 으며, 금연 및 비만 펀드를 운영하는 등의 건강증진활동도 전개하고 있다. 


\section{Conclusion}

본 연구는 국내 모 조선업에서의 직무스트레스 관리에 대 한 사례를 설명하고 있다. 이를 바탕으로 활동의 효과를 언 급하고, 운영하는 동안 발견된 문제점들을 기반으로 사업장 에서의 직무스트레스 관리의 개선방향을 제시하고자 한다.

첫째, 사업장에서의 경영진의 관심을 바탕으로 한 종합관 리시스템이 구축되어야 한다. 직무스트레스의 원인은 매우 다양하며, 한 가지 요인에 의한 발생보다는 복합적으로 작용 한다. 또한 직무스트레스로 인한 결과도 뇌심혈관계 질환, 정신 질환, 알코올중독 등 다양한 형태로 나타난다. 즉, 어떤 한 분야의 전문가나 인프라만 구축되어서는 적절한 조치가 어렵기 때문에 보건 관리자, 인사부서 담당자, 전문 상담사, 의료인력과 관련 장비와 같은 다양한 분야에서의 인프라 구 축이 필수적이다.

둘째, 종합관리시스템 운영을 모니터링할 수 있는 전산시 스템이 구축되어야 한다. 특히, 조선업의 경우에는 복잡한 작업, 구조물의 위험성 등 타 산업과 다른 특성을 가지고 있 기 때문에 직무스트레스 측정, 음주, 흡연 등의 생활습관, 과 거병력, 인사기록 등과 같은 데이터와 함께 작업환경 관련 데이터가 연계된 전산시스템이 사전에 구축되어, 지속적으로 모니터링할 수 있어야 한다.

셋째, 직무스트레스에 대한 인식 변화에 많은 노력을 기울 여야 한다. 아직까지 우리나라 정서상 직무스트레스와 관련 된 현상들을 선입견을 가지고 정신 질환으로 받아 들일 수 있다. 따라서 좋은 관리시스템을 운영하고 있음에도 활동에 대한 실적이나 관심도가 매우 떨어질 수 있다. 따라서 직무 스트레스 관리와 함께 인식 변화를 위한 홍보활동도 병행되 어야 한다. 그리고 시행 초기에는 사내 업무 메일시스템 및 전화를 통한 익명 상담창구를 같이 운영하는 것이 매우 도움 이 될 것으로 판단된다.

넷째, 신입사원에 대한 초기 대응(직무스트레스 교육)이 필요하다. 신입사원의 경우는 아직 조직 내 갈등, 작업에 의 한 직무스트레스 등의 경험이 없거나 비교적 적은 대상이라 할 수 있다. 따라서, 직무스트레스 자가조절을 위한 명상법, 대처기술에 대한 능력 향상을 위한 교육이 선행되면 사후에 대한 관리보다 소요되는 시간, 비용 등을 줄이는데 큰 효과 가 있을 것이다.

마지막으로 직무스트레스 관리와 함께 흡연, 비만, 음주는 줄이고 운동, 웃음은 권장하는 등의 개인 건강증진활동 전개 가 필요하다.

직무스트레스 관리에 있어 중요한 점은 직무스트레스가 개인의 문제로만 해석하여 받아들이기 보다는 노동력 상실 로 인한 회사의 생존과 관련됨을 인식하고 조직적인 차원에
서의 문제점으로 받아들이고 예방에 힘써야 하겠다.

\section{References}

Choi, J. W., Development and apply for a health risk index to manage for Stress and cerebro-cardiovascular disease, Korea Employers Federation, 2005.

Choi, S. Y., Kim, H. S., Kim, T. H. and Park, D. H., A study on Job Stress and MSDs(Musculoskeletal Disorders) of Workers at Automobile Manufacturing Industry, Journal of the Korean Society of Safety, 20(3), 202-211, 2005

Han, S. H., Cho, S. H., Kim, J. Y. and Sung, N. J., Importance of Job Demands, Career Development, Role Pressure, and Economic-IssueRelated Job Stress as Risk Factors for Work Related Musculoskeletal Disorders in Electronics Assembly Line Workers, Korean Society of Occupational \& Environment Medicine, 15(3), 269-280, 2003.

Hemingway, H. and Marmot, M., Psychosocial factors in the aetiology and prognosis of coronary heart disease: systematic review of prospective cohort studies, British Medical Journal, 318, 1460-1467, 1999.

Hong, T. S., An Empirical Study on The Stress Influences on the Job Attitudes toward the Employees of the Shipbuilding Industry Workers, Department of Business Administration, Graduate School, Chosun University, 2011.

Health and Safety Executive, Self-reported work-related illness in 1998/99: results from EURO-STAT ill-health module in the 1999 labour force survey summer quarter. London, Health and Safety Executive, 1999.

Jung, K. H., Kim, Y. C., Kang D. M. and Kim J. W., Study of Relation Between Work-Related Musculoskeletal Disorders-Psychiatric Disorders and Job Stress in Train Drivers, Journal of the Ergonomics Society of Korea, 27(1), 1-7, 2008

Kang, S. C., The Occupational Stress Levels of Elementary School Teacher and the Methods to Coping the Stress, Major in Elementary Physical Education, Graduate School, Gongju National University of Education, 2004

Kim, K. J. and Chang, S. R., A Plan for Improving Shipbuilding Industry Foreman's Work Ability by Managing the Job Stress, Journal of the Korean Society of Safety, 26(2), 77-82, 2011.

Kim, Y. C. and Bae, C. H., Study of the Relation between Work-Related Musculoskeletal Disorders and Job Stress in Heavy Industry, Journal of the Korean Society of Safety, 21(4), 108-113, 2006.

KOSHA, The method to evaluate for job stress, KOSHA, 2005.

KOSHA, Guide for manual job stress, KOSHA, 2006.

Lee, S. W., Job Stress in Nursing, Korean Nurses Association, 23(4), 2-37, 1984.

Park, Y. S. and Heo, W. J., The Relationship between Job Stress and Psychosocial Stress in Telecommunication Service Workers, Korea Safety Management \& Science, 7(3), 73-84, 2005.

Pattani, S., Constantinovici, N. and Williams, S., Who retires early from the NHS because of ill health and what does it cost? A national cross 
sectional study, British Medical Journal, 322(7280), 208-209, 2001 Rozanski, A., Bairey, N., Krantz D., Friedman, J., Resser, K., Morell, M., Hilton-Chalfen, S., Hestrin, L., Bietendorf, J. and Berman, D., Mental stress and the induction of silent myocardial ischemia in patients with coronary artery disease, The New England Journal of Medicine, 318, 1005-1012, 1988.

Song, M. J., Lee, J. S., Kim, Y. C. and Yoon, H. Y., A Study on Job Stress of Aircraft Maintenance Workers, Fall Conference of Ergonomics Society of Korea, 2007.

Yoon, H. Y. and Park, J. J., A Study on Job Stress of Workers at Distribution Industry, Journal of the Society of Korea Industrial and Systems Engineering, 31(4), 2008.
Yu-Chang Kim: yckim@deu.ac.kr

Highest degree: Ph.D., Department of Industrial Engineering, KAIST Position title: Professor, Department of Industrial Management Engineering, Dong-eui University

Areas of interest: Ergonomics, Industrial Safety, WMSDs, Job Stress, Human Error

Date Received : 2012-01-06

Date Revised :2012-01-10

Date Accepted : 2012-01-13

\section{Author listings}

Chang-Ho Bae: Changho.bae@samsung.com

Highest degree: Ph.D. Candidate, Department of Industrial Management Engineering, Dong-eui University

Position title: Assistant Manager, Group of HSE, Samsung Heavy

Industry

Areas of interest: Ergonomics, Industrial Safety, WMSDs, Job Stress,

Human Error 